\title{
The representation of dust transport and missing urban sources as major issues for the simulation of PM episodes in a Mediterranean area
}

\author{
E. Flaounas ${ }^{1, *}$, I. Coll ${ }^{1}$, A. Armengaud ${ }^{2}$, and C. Schmechtig ${ }^{1}$ \\ ${ }^{1}$ LISA, CMC, 61 avenue du Général de Gaulle, 94010 Créteil Cedex, France \\ ${ }^{2}$ AtmoPACA, 146 rue Paradis, 13006 Marseille, France \\ * now at: LATMOS, IPSL, Université Pierre et Marie Curie, CNRS, Paris, France
}

Received: 18 May 2009 - Published in Atmos. Chem. Phys. Discuss.: 15 July 2009

Revised: 7 October 2009 - Accepted: 8 October 2009 - Published: 27 October 2009

\begin{abstract}
Due to its adverse effects on human health, atmospheric particulate matter (PM) constitutes a growing challenge for air quality management. It is also a complex subject of study. The understanding of its atmospheric evolution is indeed made difficult by the wide number of sources and the numerous processes that govern its evolution in the troposphere. As a consequence, the representation of particulate matter in chemistry-transport models needs to be permanently evaluated and enhanced in order to refine our comprehension of PM pollution events and to propose consistent environmental policies. The study presented here focuses on two successive summer particulate pollution episodes that occurred on the French Mediterranean coast. We identify and analyze the constitutive elements of the first and more massive episode and we discuss their representation within a eulerian model.

The results show that the model fails in reproducing the variability and the amplitude of dust import from western Africa, and that it constitutes a strong bias in PM daily forecasts. We then focus on the lack of diurnal variability in the model, which is attributed to missing urban sources in standard emission inventories, and notably the resuspension of particles by urban road traffic. Through a sensitivity study based on PM and $\mathrm{NO}_{\mathrm{x}}$ measurements, we assess the sensitivity of PM to local emissions and the need to reconsider road traffic PM sources. In parallel, by coupling the CHIMERE-DUST model outputs to our simulation, we show that the representation of transcontinental dust trans-
\end{abstract}

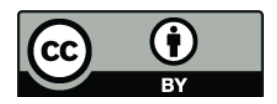

Correspondence to: E. Flaounas (flaounas@aero.jussieu.fr) port allows a much better representation of atmospheric particles in southern France, and that it is needed in the frame of air quality management for the quantification of the anthropogenic part of particulate matter pollution.

\section{Introduction}

Besides its importance in influencing climate (Charlson, 1992), particulate matter of anthropogenic origin is a main component of atmospheric pollution and is responsible for the lack of visibility in urban centers (Park and Kim, 2005; Vallius et al., 2005; Wåhlin et al., 2006; Lonati and Giugliano, 2006). Its impact on human health is now widely recognized; many studies indeed showed that atmospheric particles can easily enter respiratory airways, with a depth of inhalation and a deposition rate depending on their size, shape, physical and chemical properties (Monn, 2001; Moschandreas and Saksena, 2002). Epidemiological studies have demonstrated the association between the exposure to $\mathrm{PM}_{10}$ and $\mathrm{PM}_{2.5}$ (particulate matter with a diameter lower than $10 \mu \mathrm{m}$ and $2.5 \mu \mathrm{m}$, respectively) and all-cause mortality, among which lung-cancer and cardiopulmonary mortality are listed (Scoggins, 2004). Recently, (Larrieu, 2007) confirmed that current levels of $\mathrm{PM}_{10}$ and nitrogen dioxide in several European cities are linked to a short term increase of cardiovascular morbidity. Since 1999, the European Union has set limit values for $\mathrm{PM}_{10}$ for the protection of human health over different averaging periods, so as to represent various exposure durations. A 24-h limit value of $50 \mu \mathrm{g} / \mathrm{m}^{3}$ was fixed, not to be exceeded more than 35 times a year. Since 2005, the annual limit value for $\mathrm{PM}_{10}$ is set to

Published by Copernicus Publications on behalf of the European Geosciences Union. 
$40 \mu \mathrm{g} / \mathrm{m}^{3}$. Van Dingenen et al. (2004) and Yttri (2005) reported that, at the beginning of the 2000s, this last standard was exceeded at all near-city, urban and kerbside places in Europe, while the annual limit value of $40 \mu \mathrm{g} / \mathrm{m}^{3}$ was still over passed in several areas. Their studies also revealed that for hourly values, the $50 \mu \mathrm{g} / \mathrm{m}^{3}$ threshold was extensively exceeded, especially in Italy ( 87 days per year), and that an upward trend in $\mathrm{PM}_{10}$ baseline was observed since 2000 in some European countries.

In urban and suburban areas, the major sources of anthropogenic aerosols are road traffic and fossil fuel burning emissions, as well as combustion and soil-related industrial activities (Kaur et al., 2007; Yatkin and Bayram, 2007). Nevertheless, the background $\mathrm{PM}_{10}$ levels are mainly composed of mineral crustal particles, and it is common that long-range transport of natural aerosols strongly participates in high local PM episodes. Indeed, Saharan dust outbreak events have been shown to be responsible for short-term sharp increases in $\mathrm{PM}_{10}$ concentrations in the boundary layer over the western and eastern Mediterranean, and were associated to frequent exceedances of the EU limits for $\mathrm{PM}_{10}$ (Viana, 2002; Rodriguez, 2004; Moreno, 2005; Ganor, 2009), with peak values that could exceed $200 \mu \mathrm{g} / \mathrm{m}^{3}$ during $48 \mathrm{~h}$ for severe events (Sánchez et al., 2007). Numerous studies have described and discussed the importance of such dust import to Spain (Rodriguez et al., 2002; Lyamani et al., 2005; Salvador, 2008), and Italy (Gariazzo et al., 2007; Barkan, 2005; Mona, 2006). Several studies also focused on the import of dust to different parts of Europe (e.g. Viana, 2008), but to our knowledge no French data have been discussed in this context. Only the very recent study of Querol et al. (2009) proposes a comparison of dust impact across the Mediterranean basin, including three sites in southern France. These data support the possibility of a significant impact of African dust on this area.

Eulerian models that simulate the transport and the transformation of aerosols and gases constitute an important tool to enhance our knowledge about aerosol pollution events, and to develop efficient action plans to reduce the atmospheric levels of particulate matter (Ilacqua et al., 2007; Turpin, 2000; Thunis, 2007). However, in these models, the anthropogenic and terrestrial fractions of particulate matter need to be better described and quantified. Model intercomparisons, but also single evaluations of models against measurements, have been conducted in order to evaluate our current capabilities to perform comprehensive PM modeling (Bessagnet et al., 2004; Monteiro et al., 2007; Sartelet et al., 2007; Stern et al., 2008). The results helped to gain confidence in the simulation of the chemical constituents of particulate matter and showed that models were able to capture the general variability of PM during the simulated periods. However, they also highlighted some deficiencies in the models, which often lead to an underestimation of modeled PM concentrations relative to observations. These deficiencies have been attributed to the choice of the physical and chemical pa- rameterizations (including secondary organic aerosol (SOA) production), to meteorological input fields and the associated parameterization of vertical exchanges in the atmosphere, to the treatment of badly known sources, to long-range transport of dust particles, but also to the precision of measurements used for comparison. In addition, the studies indicate that errors in the emission data are important sources of uncertainty, that may reach $20 \%$ on a total anthropogenic annual basis for Europe, while they are known to be considerably larger for individual model grid points and short time scales (hours to days). In consequence, the exploration of particulate pollution case studies remains necessary to better identify the nature of particulate pollution events and to provide new directions to ameliorate eulerian model realism, for an improved air quality management.

The study presented here focuses on the simulation, with the CHIMERE eulerian model, of $\mathrm{PM}_{10}$ concentrations in the south of France during two successive PM episodes that occurred in the month of June 2006. It aims at understanding the constitutive elements of this episode, at evaluating the ability of the model to restitute those elements, and at identify the elements in the model that can be enhanced for a better simulation and forecast of similar phenomena. This study was conducted in close cooperation with Atmo PACA, which is the public association in charge of air quality monitoring and modeling in the Provence-Alpes-Côte d'Azur (PACA) region. After the presentation of the site of the study and of the CHIMERE model configuration, we will analyze the ground-based observations of $\mathrm{PM}_{10}$ during the selected pollution event and compare them with the model outputs. In a second part, sensitivity studies will help identifying the origin of the gaps between the model and the measurements, and some possibilities to enhance the representation of $\mathrm{PM}_{10}$ in the model will be discussed.

\section{Presentation of the study}

\subsection{Site and measurement data}

In this study we focus on the western greater part of the PACA region. The domain is characterized by a complex topography (Fig. 1): it is covered with mountains (which don't exceed the altitude of $1000 \mathrm{~m}$ ) forming two valleys (of Rhône and of Durance) while to the south lays the Mediterranean Sea. The largest city of this area is Marseille, which population is of about 820000 inhabitants. Other large urban centers are Toulon, Avignon, Aix and Arles. A large industrial complex is located in Berre, $50 \mathrm{~km}$ to the west of Marseille. Among the numerous stations measuring pollutants over the area, $\mathrm{PM}_{10}$ are measured using a Tapered Element Oscillating Microbalance in 5 urban areas and 1 industrial area on the simulation domain. Measurements of $\mathrm{NO}_{\mathrm{x}}$ and basic meteorological parameters such as wind strength and direction are also conducted at several of the 6 stations 


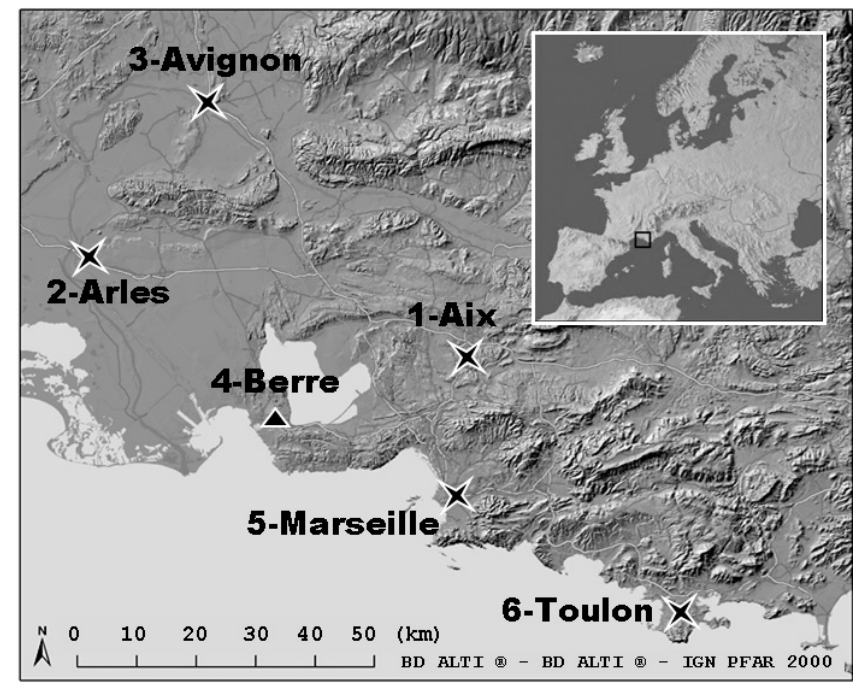

Fig. 1. Presentation of the simulation domain and location of the urban (black star) and industrial (black triangle) $\mathrm{PM}_{10}$ measurement sites.

listed above. Two types of atmospheric circulation prevail on the region: Mistral and sea breeze conditions. The Mistral is a strong wind flowing from the north which eventually turns easterly as it propagates towards the South due to the sea-land temperature contrast. As a consequence, it mostly affects the western and central parts of the domain, with an expected beneficial effect on air quality due to strong atmospheric dilution (Salameh, 2007). Sea breeze circulation is associated with low winds blowing from the south. Figure 2 presents the wind rose plot for June and July 2006 and the associated mean $\mathrm{PM}_{10}$ concentrations at the Marseille groundbased station. It shows evidence that the sea breeze (southwest, south-east direction) is associated with the greatest frequency and with high $\mathrm{PM}_{10}$ concentrations, probably due to $\mathrm{PM}$ advection from the urbanized coast, but also due to longrange transport of particles. On the reverse, Mistral events $\left(310^{\circ}-340^{\circ}\right)$ show stronger wind speeds and are accompanied with a drop in particulate pollution intensity. The western area of Arles-Avignon is the most exposed to Mistral events, while the whole region is exposed to the slow advection of air masses by the sea breeze in low-dispersion conditions, as air masses are further blocked by the large mountainous volumes laying to the north-east (Drobinski, 2007). Its intense emissions, but also its southern location, make of this region the most polluted area in France in terms of ozone but also in terms of particulate matter, with $50 \%$ of the days having a non good quality of air. Thus, the $\mathrm{PM}_{10} 24 \mathrm{~h}$-limit of $50 \mu \mathrm{g} / \mathrm{m}^{3}$ is exceeded 43 to 116 times a year at several urban sites (especially in Marseille and Toulon), while only 35 excess are tolerated per year.
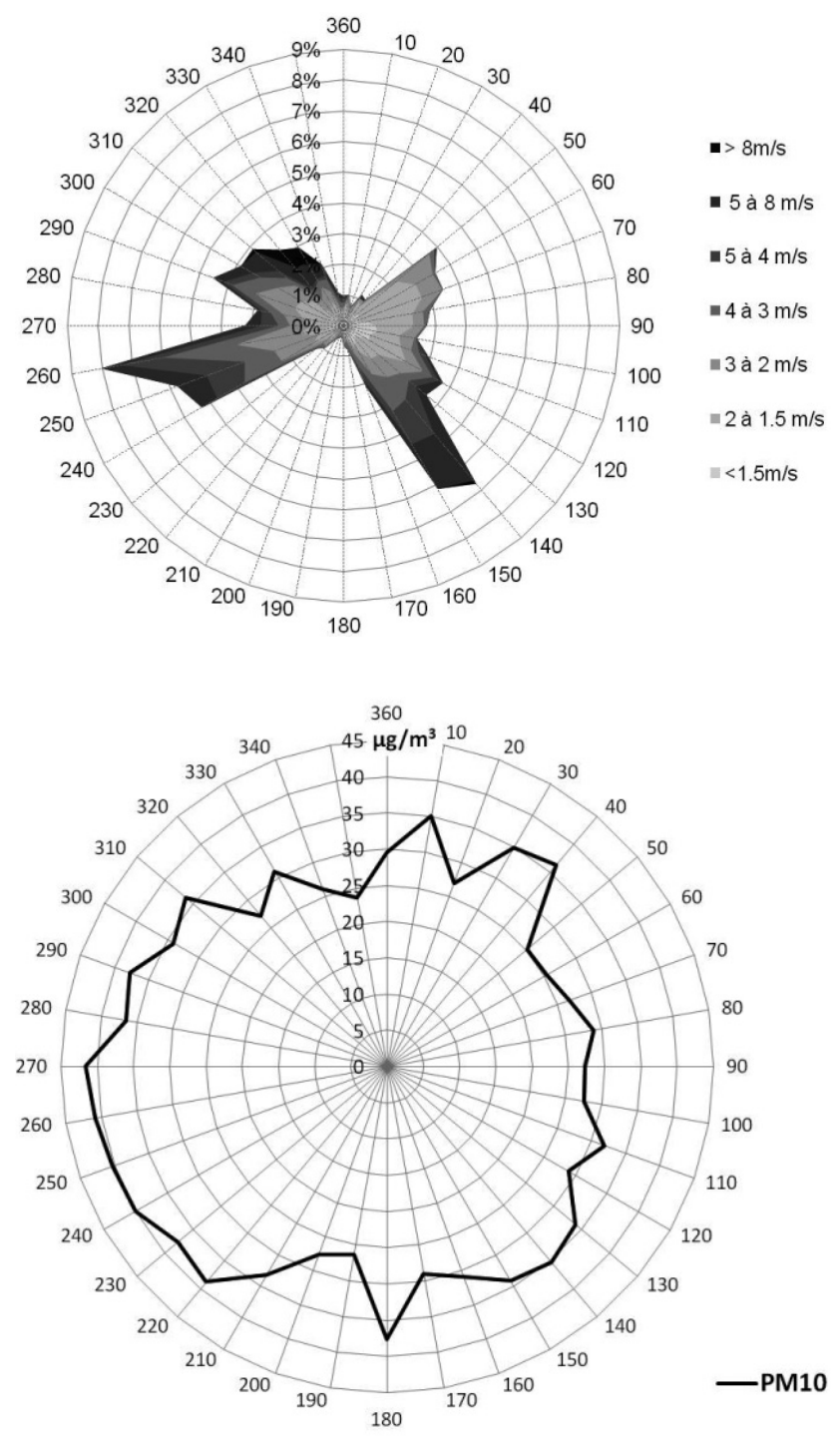

Fig. 2. Wind (top) and PM concentration (bottom) sector plots at Arles for June and July 2006.

\subsection{Model configuration}

For this study we used the Chemistry Transport Model CHIMERE (http://www.lmd.polytechnique.fr/chimere/). The model was first run on a domain covering the entire PACA region with an horizontal resolution of $9 \mathrm{~km}$ and forced at its boundaries by the national and continental PREV'AIR simulations (http://www.prevair.org). In a second step, the model was run over a nested domain with a finer horizontal resolution of $3 \mathrm{~km}$ along $41 \times 51$ grid points, covering all the urban agglomerations shown in Fig. 1. On the vertical, the domain is divided into 8 levels from the ground to $750 \mathrm{hPa}$.

The chemical scheme is the reduced MELCHIOR2 mechanism (Lattuati, 1997), which is composed of 44 species 


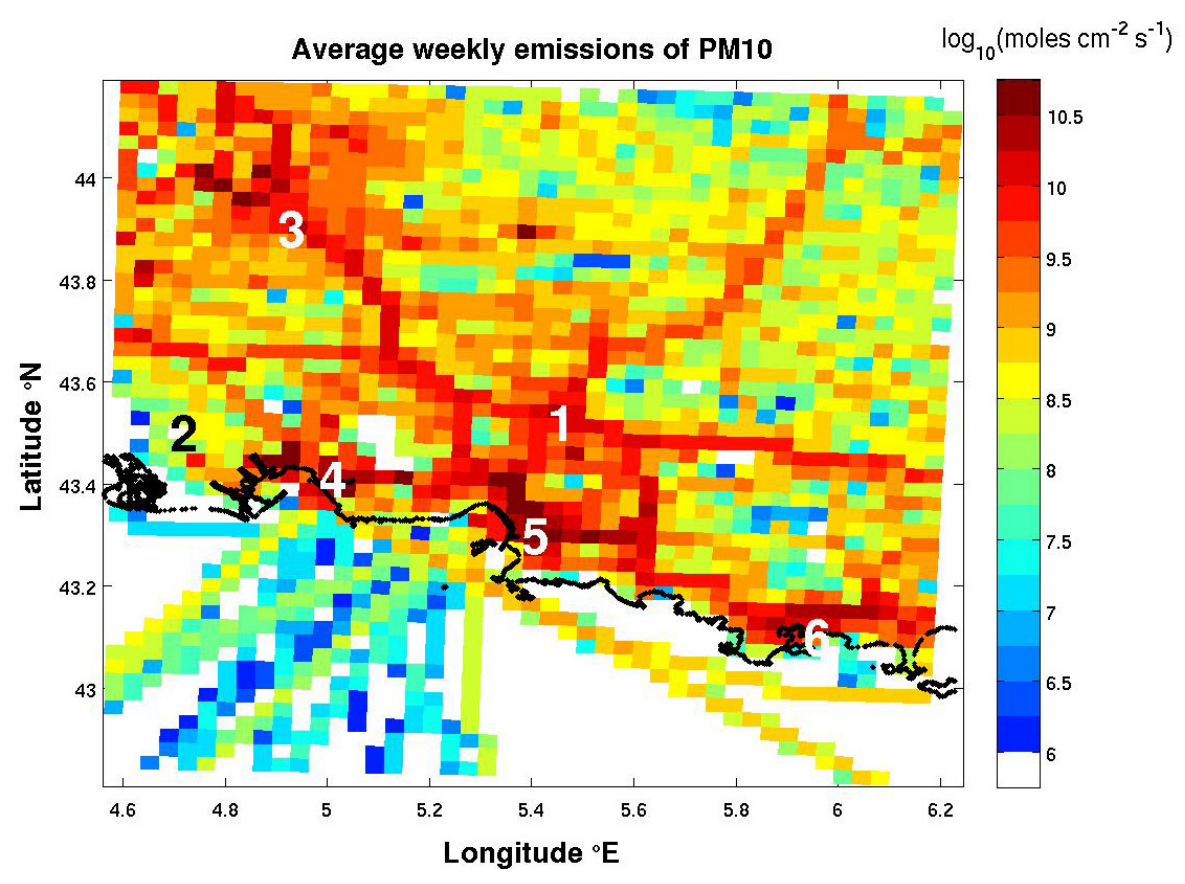

Fig. 3. Anthropogenic emissions of NOx from the regional Atmo PACA inventory. The numbers correspond to the measurement sites listed in Table 1 .

including 19 organic species and 120 reactions. Photolysis rates are calculated under clear sky conditions as a function of height using the TUV model of Madronich (1998). Dynamical calculations were provided by the MM5 meso-scale model (http://www.mmm.ucar.edu/mm5/) running at the same horizontal resolution as CHIMERE. The CHIMERE aerosol module accounts for 8 species (primary particulate matter - including not only black carbon and organic carbon but also industrial mineral dusts - nitrate, sulfate, ammonium, biogenic and anthropogenic secondary organic aerosol - SOA - sea salts and water) and uses 6 size bins from $10 \mathrm{~nm}$ to $40 \mu \mathrm{m}$. Physical processes taken into account are the following:

- Coagulation is calculated from the theory used by Gelbard (1980)

- Absorption is taken into account for both inorganic and organic species. For inorganic species, equilibrium concentrations are computed with a tabulated version of the thermodynamic module ISORROPIA (http:// nenes.eas.gatech.edu/ISORROPIA). For secondary organic species, equilibrium concentrations are calculated through a temperature dependent partitioning coefficient (Pankow, 1994).

- Concerning nucleation, the parameterization of Kulmala (1998) for sulfuric acid nucleation is used. This process is affected to the smallest bin in the sectional distribution. Although the nucleation of condensable organic species has been clearly identified in many experimental studies (Kavouras, 1998), no parameterization was available for this version of the CHIMERE model. However, since the sulfuric acid nucleation process competes with absorption processes, it is expected to occur in weakly particle polluted conditions.

Up to now, a very simplified scheme for SOA formation has been implemented in the chemical module MELCHIOR, based on biogenic and anthropogenic aerosol yields. In the model, precursor volatile organic compounds able to form secondary aerosol species are high chain alkanes, aromatics and monoterpenes. Mass transfer between gas and aerosol phases is not only driven by the gas phase diffusion but also by the thermodynamic equilibrium through a temperature dependent partition coefficient (see http://www.lmd. polytechnique.fr/chimere/) for more details). Aqueous sulphate chemistry is considered, as well as a few heterogeneous reactions relative to nitric acid chemistry. Dry deposition for model gas species is parameterized as a downward flux from Wesely (1989). Dry deposition for aerosols also makes use of a resistance scheme.

Anthropogenic emissions are provided by the kilometrical regional inventory developed by Atmo PACA with a bottom-up approach for air quality forecast, last updated in 2006 and which considers $\mathrm{NO}_{\mathrm{x}}$, speciated volatile organic compounds, $\mathrm{SO}_{2}, \mathrm{CO}, \mathrm{PM}_{10}$ and $\mathrm{PM}_{2.5}$ from fixed industrial sources, mobile sources, and biogenic sources (AIRMARAIX, 2005). Concerning PM emissions, the inventory (Fig. 3) reveals an important participation of the industrial 
sector (approximately $60 \%$ of the regional emissions) associated to punctual sources in the industrial area of Berre, at the west of Marseille, followed by road transports (approximately 30\%). However, the weight of the road transport sector increases to $40 \%$ if we consider the finest particles (especially $\mathrm{PM}_{2.5}$ ). It is necessary to note here that the inventory of PM sources is not exhaustive. In particular, the diffuse emissions of industrial fabrics, the agricultural sector, the particles stemming from the wear of tires, brakes and roads and their resuspension due to road traffic are not taken into consideration here, as in many current inventories, due to a lack of data. Biogenic emissions of isoprene and terpenes are parameterized as fluxes depending on temperature and insulation.

The evaluation of CHIMERE is processed everyday at Atmo PACA through a statistic evaluation of the model air quality forecasts against the ground-based network of chemical and meteorological measurements. The results are very satisfactory for gaseous pollutants, but show an underestimation of the observed $\mathrm{PM}_{10}$ levels. Concerning meteorology, the ability of MM5 to restitute the local air mass circulations on this area was shown in the frame of a previous modeling and measurement program (Pirovano, 2007). The simulations were conducted for the whole June and July periods with hourly outputs.

\section{Analysis of the episode simulation}

The model was run over the whole period in the configuration described above. The simulated $\mathrm{PM}_{10}$ concentrations were compared to observations and analyzed, so as to evaluate the ability of the model to perform comprehensive PM simulations.

\subsection{Regional features}

\subsubsection{PM episode restitution}

In Fig. 4 (upper graph) are represented the time series of the daily mean $\mathrm{PM}_{10}$ concentrations measured at all the PACA stations during the period of June-July 2006. The observations reveal a mean PM background of 20 to $30 \mu \mathrm{g} / \mathrm{m}^{3}$. This value is consistent with longer term observations, as described in the annual air quality reports of this region (AtmoPACA, 2008). However, during this period, the measured concentrations twice overstep the limit of $50 \mu \mathrm{g} / \mathrm{m}^{3}$ : from 18 to 21 June and from 25 to 30 June. The PM maxima then reach 60 to $75 \mu \mathrm{g} / \mathrm{m}^{3}$. These episodes of particulate pollution can be associated to synoptic influences and not to local phenomena, as the peaks are observed at all sites and prove to be correlated site by site.

We can notice from the lower graph (modeled values) that the model is able to capture the main features of the dayto-day variability of $\mathrm{PM}_{10}$ during the whole period. The correlation between observations and model outputs varies
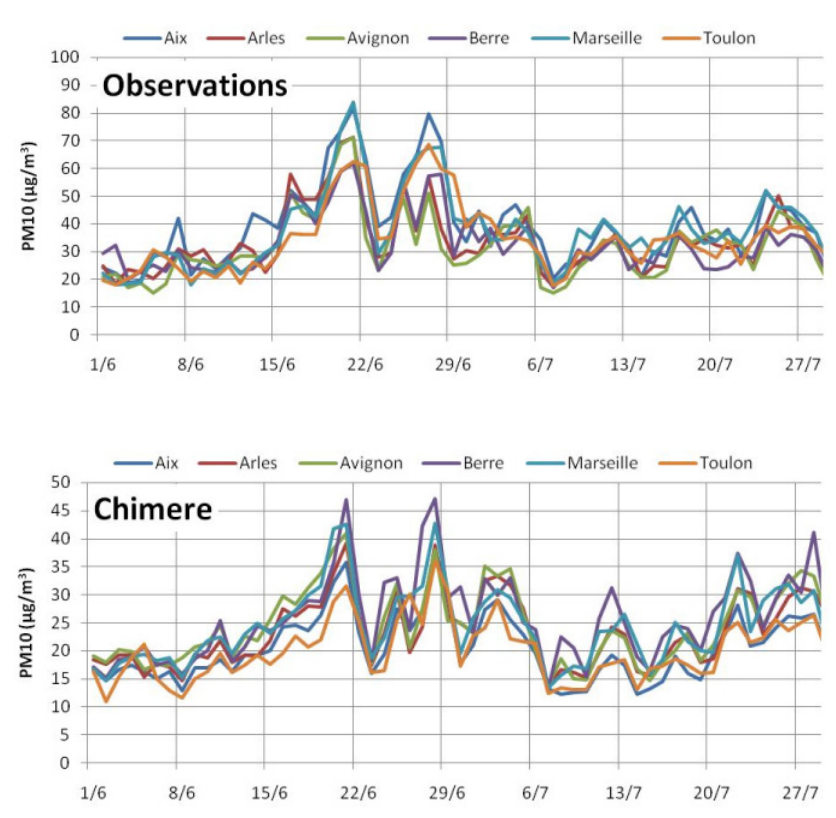

Fig. 4. Observed (upper graph) and modeled (lower graph) daily mean concentrations of $\mathrm{PM}_{10}$ at the 6 measurement sites

between $r^{2}=0.4$ (for Arles) and $r^{2}=0.61$ (for Marseille) for daily mean concentrations. During the first two days of the second episode, the western part of the domain (Avignon, Arles) is exposed to a minor Mistral event making the PM peaks much lower than in the other areas. The geographical extent of this meteorological phenomenon is overestimated in the model, which simulates a decrease of $\mathrm{PM}_{10}$ in all stations. This point does not constitute a bias of the model. However, when comparing the simulated daily mean time series with the observations, it appears that the model systematically underestimates the particulate pollution levels (i) by $10 \mu \mathrm{g} / \mathrm{m}^{3}$ (factor of 1.5) during the non-event days and (ii) by $25 \mu \mathrm{g} / \mathrm{m}^{3}$ (factor of 2) during the two episodes of June.

\subsubsection{Analysis of the episode}

We focused on the first episode, which peaks on 21 June. Due to its regional amplitude, we investigated the possibility of large-scale transport of aerosols to the simulated area, through a back trajectory analysis for the whole period. The NCEP Final analysis (FNL) showed that during the episode high pressures were prevailing over western Mediterranean. Rodriguez et al. (2001) showed that similar meteorological conditions (anticyclonic circulations) were responsible for PM pollution episodes over Spain, by driving air masses from north Africa to southern France.

Figure 5 presents 4-day back trajectories for the air masses arriving at the southern border of our simulation domain on 21 June, as generated by the HYSPLIT model from FNL (http://www.arl.noaa.gov/HYSPLIT.php). In parallel, we analyzed Angstrom coefficient values (Fig. 5) acquired 

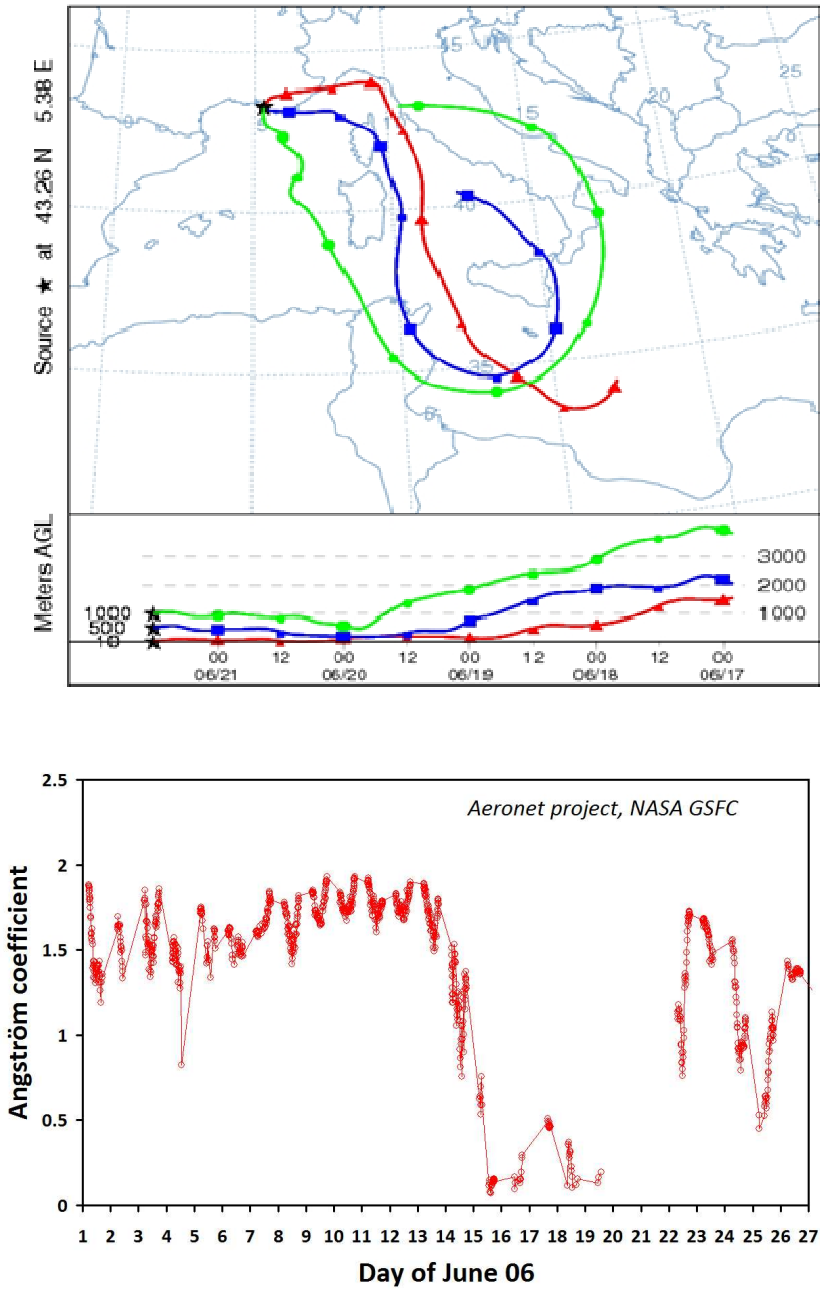

Fig. 5. Four-day back trajectories arriving at Toulon on June 21 (upper panel, http://www.arl.noaa.gov/HYSPLIT.php) and Angstrom coefficient (Level 2.0 AOT) evolution in Toulon for June 2006 (lower panel, http://aeronet.gsfc.nasa.gov/).

in Toulon within the frame of the AERONET project (http: //aeronet.gsfc.nasa.gov/) as well as Aerosol Index (AI) maps (not shown here) generated by TOMS, NASA (http://toms. gsfc.nasa.gov/aerosols) for the month of June 2006. Those data (see Fig. 5) well show that Mediterranean air masses arriving at our domain on 21 June are associated with low values of the 440-870 Angstrom coefficient, which clearly identifies a dust event during the 15-19 June period, most likely extending to 21 June according to the values calculated for 22 June. Unfortunately, no data is available between 26 June and 29 June. At the same time, elevated AI values over the western Mediterranean confirm the existence of significant dust outbreak events. The AI indeed overpasses the value of 1.0 in the region of north Africa - west Mediterranean sea, signifying the existence of aerosols absorbing UV radiation and which can be considered as dust aerosols. Such an approach was previously used by Lyamani et al. (2005) to demonstrate the occurrence of a similar event in southeastern Spain.

It is interesting to notice that CHIMERE represents the occurrence of the two dust events in proper time (see the temporal evolution of modeled dust at Marseille in Fig. 6), each time with a slight increase in the PM background level over the whole area. We could associate this increased level with the import of particulate matter through the southern boundary of the simulation domain. However, as large-scale CHIMERE simulations are forced at their boundaries by climatological dust concentrations, it comes out that such data are nor able to reproduce the intensity of the PM background during this period, neither to describe the variability in the composition of incoming air masses at the limits of the domain. It thus cannot provide a good representation of summer PM evolution in southern Europe.

We investigated the possibility to improve the model predictions in such situations by implementing, as boundary conditions in our run, the concentration fields of dust particles simulated by the DUST version of the CHIMERE model (http://www.lmd.polytechnique.fr/dust/) for the same period. This version of CHIMERE is dedicated to the transport of mineral particles and reproduces the emission, dry and wet deposition and transport of these particles over west Africa. Dust concentrations are represented through 20 size bins from 0.01 to $34 \mu \mathrm{m}$. The model is driven by MM5 meteorological fields and has been run for the whole year 2006 on a $1^{\circ} \times 1^{\circ}$ grid covering a rectangular domain between $90^{\circ} \mathrm{W}-$ $90^{\circ} \mathrm{E}$ and $10^{\circ} \mathrm{S}-60^{\circ} \mathrm{N}$ with 15 vertical levels from the surface to $200 \mathrm{hPa}$. More details about this version of the model can be found in Menut (2007).

Outputs are available every $12 \mathrm{~h}$. We interpolated the concentration fields so as to fit our spatial and temporal resolutions, and the 20 dust concentration classes were redistributed into our 6 larger size bins to replace our initial and boundary conditions for the dust component of the particulate matter. This simulation, called DUSTBOUND, was run for from 9 June to 24 June. The results are presented in Sect. 4.

\subsection{Local features}

A second interesting aspect of the model results concerns the modeled hourly mean concentrations. When comparing observed and simulated time series for a period without any supposed dust event, we can see (as illustrated in Fig. 7 for the Toulon grid point, with a temporal zoom on the second week of June) that CHIMERE cannot capture the intensity of the urban PM variability that results from human activity. This bias mainly finds its expression in lower peak values along the day, making difficult the restitution of urban air quality. This graph is representative of the model results at all the urban sites. 


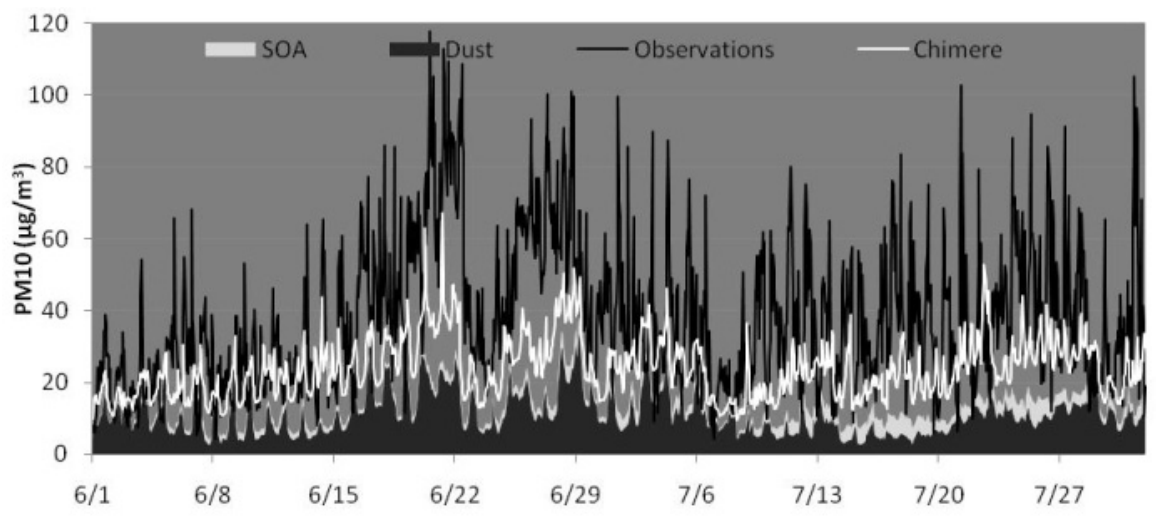

Fig. 6. $\mathrm{PM}_{10}$ hourly evolution in Marseille as calculated by CHIMERE (white line) compared to observations (black line). The simulated dust and SOA parts composing $\mathrm{PM}_{10}$ are represented as cumulative areas.

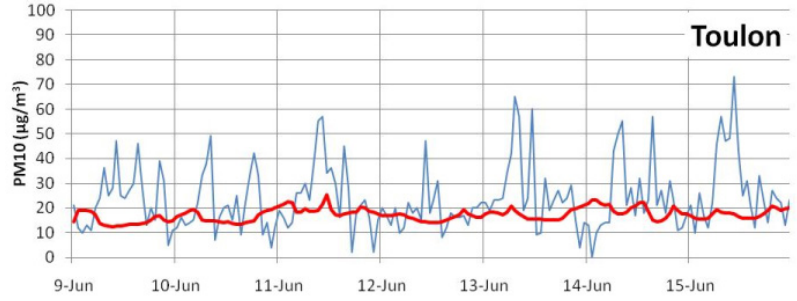

Fig. 7. Observed (blue line) and modeled (red line) $\mathrm{PM}_{10}$ concentrations in Toulon, for a representative week of the studied period.

An underestimation of the local production of secondary organic aerosol in the model may be partly responsible for the low variability in the model outputs. The underestimation of SOA is a common feature to many models (Zhang, 2007). But although this point clearly needs refinement, it may not be the main reason for the smooth aspect of the model outputs as we consider source areas and we mainly miss morning peaks.

In urban areas, the hourly variability of $\mathrm{PM}_{10}$ is mainly dependent on road traffic emissions. $\mathrm{As} \mathrm{NO}_{2}$ and $\mathrm{PM}$ urban emissions are mainly related to road traffic, we plotted (figures not shown) the observed $\mathrm{PM}_{10}$ concentrations versus the observed $\mathrm{NO}_{\mathrm{x}}$ concentrations at all urban stations during the periods with negligible wind, in order to obtain data representative of local traffic emissions. We observed a linear dependency between the two species, with a $\mathrm{PM}$ to $\mathrm{NO}_{\mathrm{x}}$ ratio of about 0.4 while in the emission inventory, the dependency between $\mathrm{PM}_{10}$ and $\mathrm{NO}_{\mathrm{x}}$ in urban cells varies between 0.1 and 0.2 only. May this result from an insufficient description of aerosol resuspension related to traffic in anthropogenic emission inventories, as discussed previously? According to recent studies, the contribution of resuspension phenomena is estimated to a level of $20 \%$ of road traffic emissions, while $20 \%$ further can be attributed to coarse fraction abrasion source emissions, the rest of emissions including com- bustion and fine fraction abrasion (Thorpe et al., 2007). In our case, the inventory $\mathrm{PM}$ to $\mathrm{NO}_{\mathrm{x}}$ ratio points out an underestimation of urban PM sources by at least a factor of 2 , which fits with the omission of resuspension and road wear sources.

We thus investigated the improvement of the model that can follow from a re-adjustment of PM urban emissions, if supplementary traffic-related sources are taken into account. We launched an empirical sensitivity test by replacing the anthropogenic particle emissions by that of $\mathrm{NO}_{\mathrm{x}}$ adjusted by a factor of 0.4 according to the observations. The sensitivity test, called EMISS, was conducted from 9 to 24 June in order to explore both periods with and without dust import. The results are presented in the next section.

\section{Sensitivity tests results}

The CHIMERE DUST simulation results reveal that the model well predicts the transport of dust particles from northwestern Africa to the Mediterranean during the third week of June 2006. The arrival of a dust plume is represented in Fig. 8 which shows dust concentration maps calculated at $800 \mathrm{~m}$ asl for 14 June and 17 June at 12:00 UT.

When used as boundary conditions, these dust concentration fields strongly impact the regional simulation of $\mathrm{PM}_{10}$. The time series in Fig. 9 present the regional model results for the reference simulation and for the simulation DUSTBOUND, together with measurements, for the grid cells of the Aix and Marseille sites, respectively. We can clearly see that the DUSTBOUND simulation better reproduces the phenomenology of a PM event than the reference run, although its intensity remains strongly overestimated ( 20 to $30 \mu \mathrm{g} / \mathrm{m} 3$ ) from 17 to 19 June. This may either follow from inaccuracies in the dust plume location or from an overestimation of its intensity during the early days of the event. However, the sudden and pronounced increase in the $\mathrm{PM}_{10}$ baseline (up to $80 \mu \mathrm{g} / \mathrm{m} 3$ ) on 16 June and its decrease on 22 June, that 

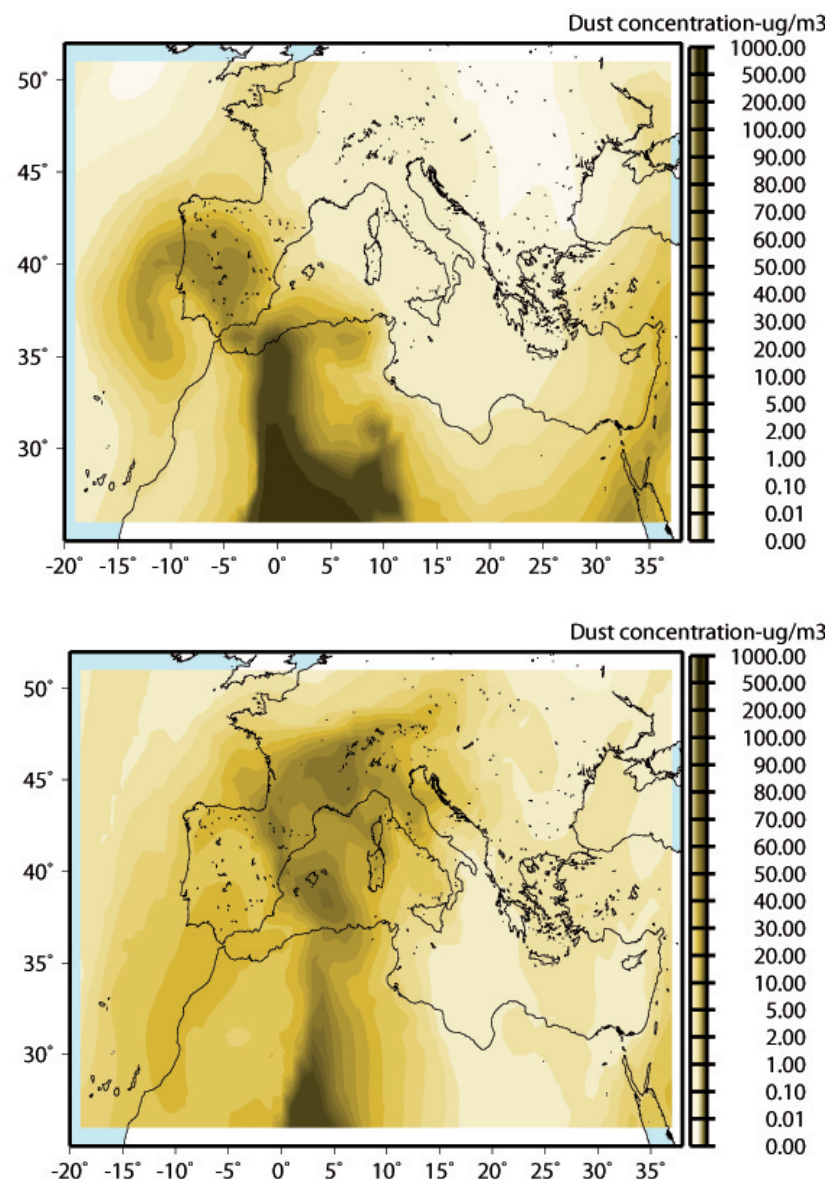

Fig. 8. Dust concentration maps (in $\mu \mathrm{g} / \mathrm{m}^{3}$ ) calculated at $800 \mathrm{~m}$ asl by CHIMERE DUST, for two selected dates of June 2006.

much better fit the observations, constitute a visible improvement of the model outputs. In this coupled configuration, the model thus proposes a more realistic PM background evolution, and provides a better understanding of particulate matter composition in the area. It shows that dust climatological values, commonly used as boundary conditions for CTMs, constitute a limitation to explain common particulate pollution events in southern Europe.

We can see that this new simulation however does not reproduce the high PM peaks observed in all urban stations during the dust event. From the observation of the large dust plumes in Fig. 8, we assumed that long-range transport of terrestrial particles may not generate such variability in the $\mathrm{PM}_{10}$ levels, and we supposed a local origin for these peaks. The results of the simulation EMISS should thus indicate us if they may originate in local urban traffic emissions.

The time series in Fig. 10 show the model outputs for the reference simulation and for the simulation EMISS, together with observations for the urban sites of Toulon and Marseille. This figure reveals a much more realistic evolution of $\mathrm{PM}_{10}$ concentrations in the simulation EMISS. Although
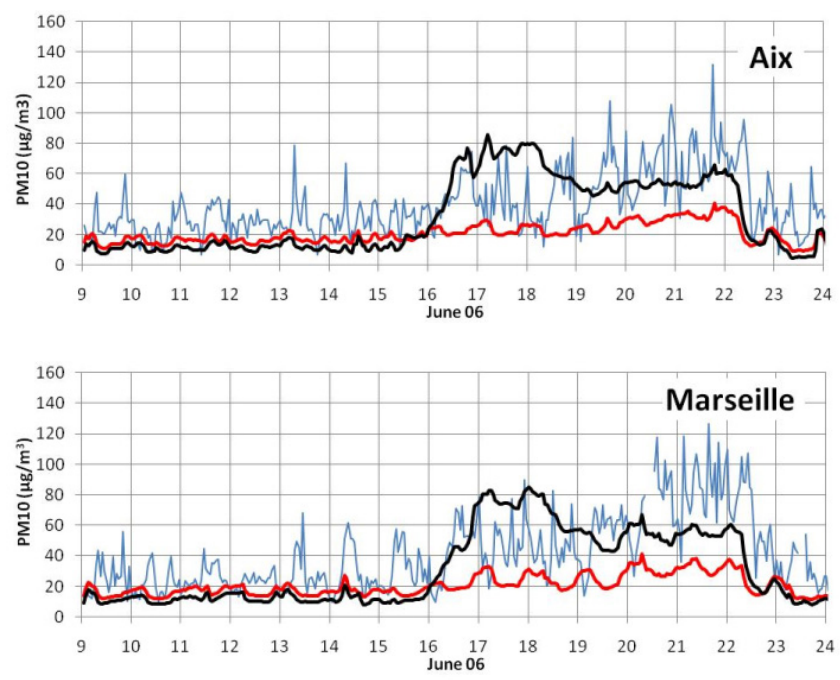

Fig. 9. $\mathrm{PM}_{10}$ time series from the reference (red line) and DUSTBOUND (black line) simulations in Aix (upper graph) and Marseille (lower graph) for the 3 selected weeks of June 2006. Observations are reported in blue.
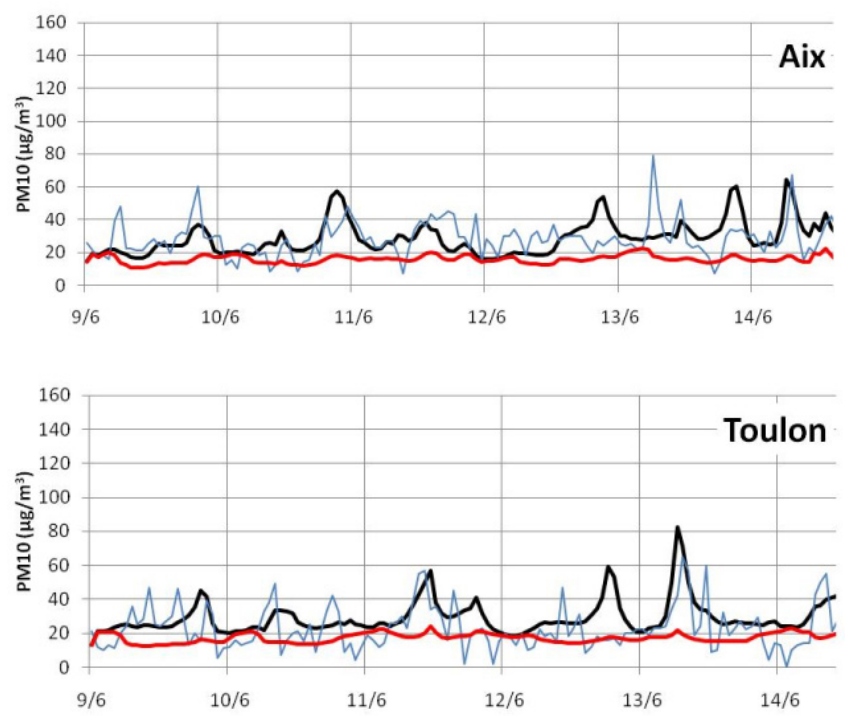

Fig. 10. Reference (red line) and EMISS (black line) simulations of $\mathrm{PM}_{10}$ concentrations in Aix (upper graph) and Toulon (lower graph) for a representative week of June 2006. Observations are reported in blue.

the exact intensity of the PM peaks measured at urban sites is not expected to be reproduced in the model due to the wellknown dilution of CTM emissions in the grid cells, the model now better captures the hourly features particulate pollution. This simulation produces $\mathrm{PM}_{10}$ peak values of the right order of magnitude, and fully restitutes in time some of the main peaks observed in urban areas. 
We have to keep in mind that, from the point of view of emission parameterization, this simulation is a simplistic one, and may not be consistent over the whole domain. However, these results highlight the fact that current anthropogenic PM emissions are underestimated in urban areas and can be easily improved using a refined empirical approach. Even if these emissions are not as influential as dust advection on the regional PM levels, their improvement remains necessary to explore the role of local PM emissions on urban air quality.

\section{Conclusions}

During the third week of June, an important episode of particulate pollution with $\mathrm{PM}_{10}$ concentrations ranging from $60-100 \mu \mathrm{g} / \mathrm{m}^{3}$ was observed in the south of France. We showed that it originated in the long-range transport of African dust, confirming that outbreak phenomena can influence particle levels in southern France even under the form of moderate episodes. This result is in agreement with the observations reported for other Mediterranean countries (Rodriguez et al., 2001, 2002; Querol et al., 2009; Mitsakou, 2008). Although the CHIMERE model was able to reproduce the nature and the timing of this episode, we show that the use of climatological values to determine the amount of dust transferred to the domain from the larger scale are insufficient to reproduce the amplitude of the event. During this episode, the simulation outputs indeed showed a negative bias reaching $25 \mu \mathrm{g} / \mathrm{m}^{3}$ over the whole region. Additionally, during all the simulation period, we highlighted a poor representation of the hourly variability of $\mathrm{PM}_{10}$ in urban cells compared to observations which was attributed to an incomplete representation of urban driving sources. Our conclusions meet those of Astitha et al. (2008) which show in their overview on regional modeling that emissions inventories and dust transport are major elements in air quality forecasts.

In the second part of this paper, the model sensitivity to urban emissions, as well as the impact of enhanced dust boundary conditions on the model outputs was investigated. Our objective was to evaluate CTM improvement strategies to better represent particulate pollution in southern places of Europe. We highlighted the need for an improvement of anthropogenic PM emission inventories, especially concerning road traffic. We showed that the current gap between inventories and observations could reach a factor of 2 for $\mathrm{PM}_{10}$ in urban centers. Quite recently, the COPERT methodology aiming at the calculation of air pollutant emissions from road transport has been updated to include resuspension by vehicles (http://lat.eng.auth.gr/ copert/). The evaluation of inventories using this methodology needs to be performed to evaluate the degree of improvement reached in the model outputs. Finally, by implementing the CHIMERE-DUST outputs at the boundaries
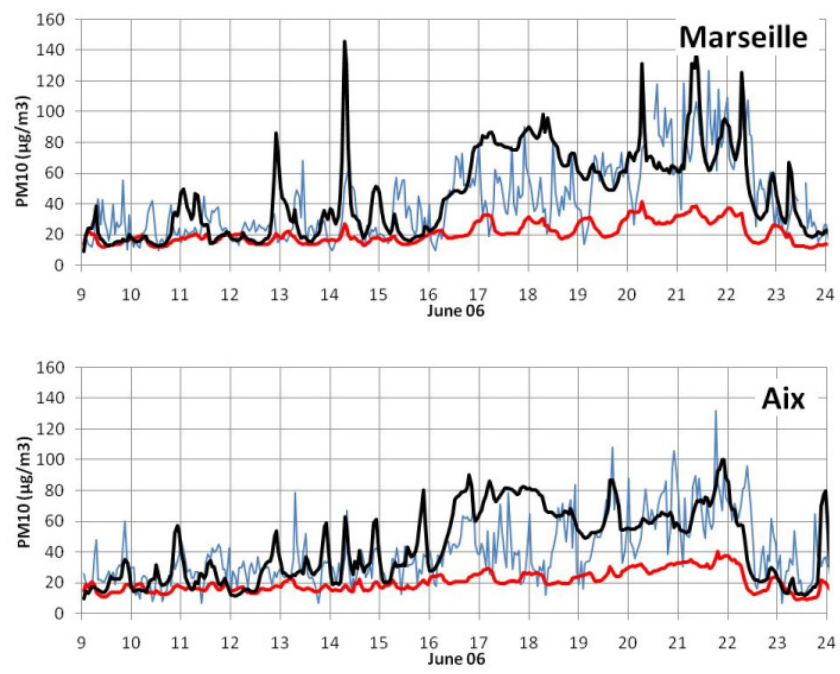

Fig. 11. $\mathrm{PM}_{10}$ in Aix (upper graph) and Marseille (lower graph) as simulated by CHIMERE in the reference configuration (red line) and for the hybrid DUSTBOUND-EMISS simulation (black line) for a 3-week period in June 2006. Observations are shown in blue.

of our domain, we showed that the use of large-scale dust emissions and transport models provide most reliable $\mathrm{PM}_{10}$ forecasts for public information, but also for $\mathrm{PM}_{10}$ event analyses and further PM pollution regulation. Indeed, the "Thematic Strategy on Air Pollution" of the European Environmental Agency that follows from the Clean Air For Europe initiative (http://ec.europa.eu/environment/archives/air/ cafe/activities/pdf/cbabaselineresults20002020.pdf) relies on modeling as its primary source of information, while using monitoring data to calibrate its chemical transport model EMEP (http://www.emep.int/). The modeled data obtained are further used in support of negotiations on emission reduction measures and for assessing of the feasibility of such measures. The precise determination of the reducible (anthropogenic) part of $\mathrm{PM}_{10}$ by models thus constitutes a challenge for Mediterranean countries within the frame of the elaboration of particle-related European directives. In this study we underline the necessity for the nesting of CTMs by a large-scale model.

In Fig. 11 we present the results of a hybrid DUSTBOUND-EMISS simulation. The time series represent the hourly values in Aix and Marseille. It clearly appears that this simulation provides more consistent results and allows quantifying more precisely the regional particulate pollution, whether we focus on background pollution or on its urban variability and intensity. The hybrid simulation is still exposed to several biases and its empirical form cannot constitute a frame for daily air quality forecasts. However, it shows that a more realistic view of the particulate levels and evolution over the area can be reached by simple improvements. 
Acknowledgements. Edited by: B. N. Duncan

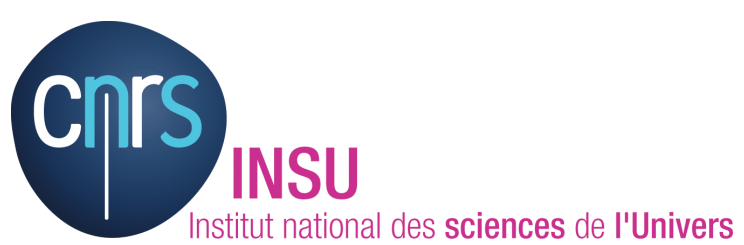

The publication of this article is financed by CNRS-INSU.

\section{References}

AIRMARAIX: Les sources d'émissions en paca, Marseille 01-10emissions-extensionregio-sf-ir02, 2005.

AtmoPACA: Surveillance de la qualité de l'air, bilan annuel 2007 Marseille, 2008.

Astitha, M., Kallos, G., and Katsafados, P.: Air pollution modelling in the Mediterranean Region: Analysis and forecasting of episodes, Atmos. Res., 89, 358-364, 2008.

Barkan, J., Alpert, P., Kutiel, H., and Kishcha, P.: Synoptics of dust transportation days from Africa toward Italy and central Europe, J. Geophys. Res., 110, D07208, doi:10.1029/2004JD005222, 2005.

Bessagnet, B., Hodzic, A., Vautard, R., Beekmann, M., Cheinet, S., Honoré, C., Liousse, C., and Rouil, L.: Aerosol modeling with chimere-preliminary evaluation at the continental scale, Atmos. Environ., 38, 2803-2817, 2004.

Charlson, R. J., Hales, J. M., Cess, R. D., Coakley, J. A., Hansen, J. E., and Hofmann, D. J.: Climate forcing by anthropogenic aerosols, Science, 255, 423-430, 1992.

Drobinski, P., Said, F., Ancellet, G., Arteta, J., et al.: Regional transport and dilution during high-pollution episodes in southern France: Summary of findings from the Field Experiment to Constraint Models of Atmospheric Pollution and Emissions Transport (ESCOMPTE), J. Geophys. Res., 112, D13105, doi:10.1029/2006JD007494, 2007.

European Environment Agency: Spatial assessment of pm10 and ozone concentrations in europe (2005), in: Technical report no 1/2009, EEA (European Environment Agency), 2009.

Gariazzo, C., Silibello, C., Finardi, S., Radice, P., Piersanti, A., Calori, G., Cecinato, A., Perrino, C., Nussio, F., Cagnoli, M., Pelliccioni, A., Gobbi, G. P., and Di Filippo, P.: A gas/aerosol air pollutants study over the urban area of rome using a comprehensive chemical transport model, Atmos. Environ., 41, 7286-7303, 2007.

Gelbard, F. and Seinfeld, J. H.: Simulation of multicomponent aerosol dynamics, J. Colloid. Interf. Sci., 78, 485-501, 1980.

Ilacqua, V., Hänninen, O., Saarela, K., Katsouyanni, K., Künzli, N., and Jantunen, M.: Source apportionment of population representative samples of pm2.5 in three european cities using structural equation modelling, Sci. Total. Environ., 384, 77-92, 2007.

Kaur, S., Nieuwenhuijsen, M. J., and Colvile, R. N.: Fine particulate matter and carbon monoxide exposure concentrations in urban street transport microenvironments, Atmos. Environ., 41, 4781-4810, 2007.
Kavouras, I., Mihalopoulos, N., and Stephanou E.: Formation of atmospheric particles from organic acids produced by forests, Nature, 395, 683-686, 1998.

Kulmala, M., Laaksonen, A., and Pirjola, L.: Parameterization for sulfuric acid / water nucleation rates, J. Geophys. Res., 103(D7), 8301-8307, 1998.

Larrieu, S., Jusot, J. F., Blanchard, M., Prouvos, H., Declercq, C., Fabre, P., Pascal, L., Le Tertre, A., Wagner, V., Rivière, S., Chardon, B., Borelli, D., Cassadou, S., Eilstein, D., and Lefranc, A.: Short-term effects of air pollution on hospitalizations for cardiovascular diseases in eight french cities: The psas program, Sci. Total. Environ., 387, 105-112, 2007.

Lattuati, M.: Contribution à l'étude du bilan de l'ozone troposphérique à l'interface de l'europe et de l'atlantique nord: Modélisation lagrangienne et mesures en altitude, Thèse de sciences, Paris 6, France, 1997.

Lonati, G. and Giugliano, M.: Size distribution of atmospheric particulate matter at traffic exposed sites in the urban area of milan (Italy), Atmospheric Environment Particulate Matter Supersites Program and Related Studies, 40, 264-274, 2006.

Lyamani, H., Olmo, F. J., and Alados-Arboledas, L.: Saharan dust outbreak over southeastern spain as detected by sun photometer, Atmos. Environ., 39, 7276-7284, 2005.

Madronich, S., McKenzie, R. L., Bjorn, L. O., and Caldwell, M. M.: Changes in biologically active ultraviolet radiation reaching the Earth's surface, J. Photochem. Photobiol. B:Biology, 46, 519, 1998.

Menut, L., Forêt, G., and Bergametti, G.: Sensitivity of mineral dust concentrations to the model size distribution accuracy, J. Geophys. Res., 112, D10210, doi:10.1029/2006JD007766, 2007.

Mitsakou, C., Kallos, G., Papantoniou, N., Spyrou, C., Solomos, S., Astitha, M., and Housiadas, C.: Saharan dust levels in Greece and received inhalation doses, Atmos. Chem. Phys., 8, 71817192, 2008, http://www.atmos-chem-phys.net/8/7181/2008/.

Mona, L., Amodeo, A., Pandolfi, M., and Pappalardo, G.: Saharan dust intrusions in the Mediterranean area : Three years of Raman lidar measurements, J. Geophys. Res., 111, D16203, doi:10.1029/2005JD006569, 2006.

Monn, C.: Exposure assessment of air pollutants: A review on spatial heterogeneity and indoor/outdoor/personal exposure to suspended particulate matter, nitrogen dioxide and ozone, Atmos. Environ., 35, 1-32, 2001.

Monteiro, A., Miranda, A. I., Borrego, C., Vautard, R., Ferreira, J., and Perez, A. T.: Long-term assessment of particulate matter using chimere model, Atmos. Environ., 41, 7726-7738, 2007.

Moschandreas, D. J. and Saksena, S.: Modeling exposure to particulate matter, Chemosphere, 49, 1137-1150, 2002.

Pankow, J. F.: An absorption model of gas/particle partitioning of organic compounds in the atmosphere, Atmos. Environ., 28, 185-188, 1994.

Park, S. S. and Kim, Y. J.: Source contributions to fine particulate matter in an urban atmosphere, Chemosphere, 59, 217-226, 2005.

Pirovano, G., Coll, I., Bedogni, M., Alessandrini, S., Costa, M. P., Gabusi, V., Lasry, F., Menut, L., and Vautard, R.: On the influence of meteorological input on photochemical modelling of a severe episode over a coastal area, Atmos. Environ., 41, 64456464, 2007. 
Querol, X., Pey, J., Pandolfi, M., Alastuey, A., Cusack, M., Pérez N., Moreno, T., Viana, M., Mihalopoulos, N., Kallos, G., and Kleanthous, S.: African dust contributions to mean ambient $\mathrm{PM}_{10}$ mass-levels across the Mediterranean Basin, Atmos. Environ., 43, 4266-4277, 2009.

Rodriguez, S., Querol, X., Alastuey, A., Kallos, G., and Kakaliagou, O.: Saharan dust contributions to PM10 and TSP levels in Southern and Eastern Spain, Atmos. Environ., 35, 2433-2447, 2001.

Rodríguez, S., Querol, X., Alastuey, A., and Plana F.: Sources and processes affecting levels and composition of atmospheric aerosol in the western Mediterranean, J. Geophys. Res., 107(D24), 4777, doi:10.1029/2001JD001488, 2002.

Salameh, T., Drobinski, P., Menut, L., Bessagnet, B., Flamant, C., Hodzic, A., and Vautard, R.: Aerosol distribution over the western Mediterranean basin during a Tramontane/Mistral event, Ann. Geophys., 25, 2271-2291, 2007, http://www.ann-geophys.net/25/2271/2007/.

Sánchez, M. L., Garcl'a, M. A., Pérez, I. A., and de Torre, B.: Ground laser remote sensing measurements of a saharan dust outbreak in central Spain. Influence on pm10 concentrations in the lower and upper spanish plateaus, Chemosphere, 67, 229-239, 2007.

Sartelet, K. N., Debry, E., Fahey, K., Roustan, Y., Tombette, M., and Sportisse, B.: Simulation of aerosols and gas-phase species over europe with the polyphemus system: Part i-model-to-data comparison for 2001, Atmos. Environ., 41, 6116-6131, 2007.

Scoggins, A., Kjellstrom, T., Fisher, G., Connor, J., and Gimson, N.: Spatial analysis of annual air pollution exposure and mortality, Sci. Total. Environ., 321, 71-85, 2004.

Stern, R., Builtjes, P., Schaap, M., Timmermans, R., Vautard, R., Hodzic, A., Memmesheimer, M., Feldmann, H., Renner, E., Wolke, R., and Kerschbaumer, A.: A model inter-comparison study focussing on episodes with elevated pm10 concentrations, Atmos. Environ., 42, 4567-4588, 2008.

Thorpe, A. J., Harrison, R. M., Boulter, P. G., and McCrae, I. S.: Estimation of particle resuspension source strength on a major london road, Atmos. Environ., 41, 8007-8020, 2007.

Thunis, P., Rouil, L., Cuvelier, C., Stern, R., Kerschbauler, A., Bessagnet, B., Schaap, M., Builtjes, P., Tarrason, L., Douros, J., Moussiopoulos, N., Pirovano, G., and Bedogni, M.: Analysis of model responses to emission-reduction scenarios within the citydelta project, Atmos. Environ., 41, 208-220, 2007.
Turpin, B., Saxena, J. P., and Andrews, E.: Measuring and simulating particulate organics in the atmosphere: Problems and prospects, Atmos. Environ., 34, 2983-3013, 2000.

Vallius, M., Janssen, N. A. H., Heinrich, J., Hoek, G., Ruuskanen, J., Cyrys, J., Van Grieken, R., de Hartog, J. J., Kreyling, W. G., and Pekkanen, J.: Sources and elemental composition of ambient pm2.5 in three european cities, Sci. Total. Environ., 337, 147$162,2005$.

Van Dingenen, R., Raes, F., Putaud, J.-P., Baltensperger, U., Charron, A., Facchini, M.-C., Decesari, S., Fuzzi, S., Gehrig, R., Hansson, H.-C., Harrison, R. M., Hüglin, C., Jones, A. M., Laj, P., Lorbeer, G., Maenhaut, W., Palmgren, F., Querol, X., Rodriguez, S., Schneider, J., Brink, H. T., Tunved, P., Tørseth, K., Wehner, B., Weingartner, E., Wiedensohler, A., and Wåhlin, P.: A european aerosol phenomenology-1: Physical characteristics of particulate matter at kerbside, urban, rural and background sites in europe, Atmos. Environ., 38, 2561-2577, 2004.

Wåhlin, P., Berkowicz, R., and Palmgren, F.: Characterisation of traffic-generated particulate matter in copenhagen, Atmos. Environ., 40, 2151-2159, 2006.

Wesely, M. L.: Parameterization of surface resistances to gaseous dry deposition in regional-scale numerical models, Atmos. Environ., (1967), 23, 1293-1304, 1989.

Yatkin, S. and Bayram, A.: Elemental composition and sources of particulate matter in the ambient air of a metropolitan city, Atmos. Res., 85, 126-139, 2007.

Yttri, K.-E., Hanssen, J. E., Tsyro, S., Lazaridis, M., Facchini M. C., and Jennings, S. G.: Transboundary particulate matter in europe - status report 2005, in: Emep report 4/2005, edited by: Tørseth, K. E. Y. a. K., 2005.

Zhang, Q., Jimenez, J. L., Canagaratna, M. R., Allan, J. D. et al.: Ubiquity and dominance of oxygenated species inorganic aerosols in anthropogenically-influenced Northern Hemisphere midlatitudes, Geophys. Res. Lett., 34, L13801, doi:10.1029/2007GL029979, 2007. 